\title{
Journal of Outdoor Recreation, Education, and Leadership
}

\section{3, Volume 5, Number 3}

ISSN: $1948-5123$

CONTENTS

PAGE

Advancing theory and improving practice: Editors' notes

Andrew Bobilya and Raymond Poff

Fostering outdoor learning experiences with urban youth through place-based expeditionary learning 179

\section{Kristen Ellison}

The effects of in-depth outdoor experience on attitudes toward nature.. 192 Masahiro Okada, Taito Okamura, and Koji Zushi

Outcomes associated with a university outdoor adventures women's canoe trip 210

Joanna Libby and Cynthia Carruthers

Environmental factors affecting the predicted decisions of backcountry skiers: An examination of the obvious clues method decision aid 226

Nate Furman, Wynn Shooter, and Jonas Tarlen

Terrain classification, climbing exposure, and technical management.... 242

Jeff Rose

Recreational deer hunting tree stand injuries in the USA: A brief review258

Phil Bishop, Nathan Frischmann, and Eric Jones

Publication made possible by the: Association of Outdoor Recreation and Education, Wilderness Education Association, and WKU Research Foundation.

Dr. Andrew Bobilya, Editor-in-Chief, Montreat College

Journal of Outdoor Recreation, Education, and Leadership (JOREL)

Articles and subscription information located at http://www.ejorel.com/ 